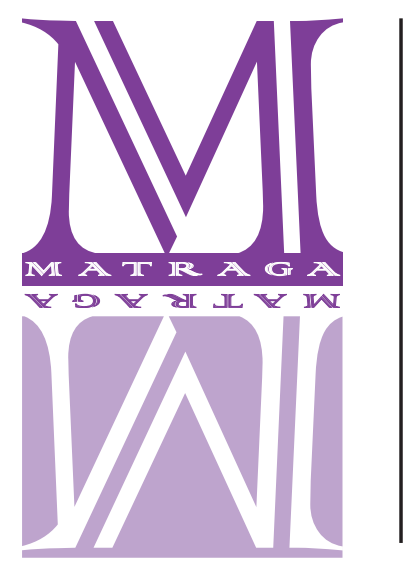

\title{
Que corpo é esse? A cidade e 0 real no conto "A unha encravada e o esmalte" (2016), de Allan da Rosa
}

\author{
Juliana Santini \\ Universidade Estadual Paulista Júlio de Mesquita Filho, Brasil \\ http://orcid.org/0000-0001-5267-7230
}

\begin{abstract}
RESUMO
Tendo como ponto de partida a discussão das formas de realização do realismo na ficção brasileira contemporânea, a reflexão aqui apresentada propõe uma análise do conto "A unha encravada e o esmalte", de Allan da Rosa, de modo a observar como a fragmentação do corpo atua na representação da cidade e de suas desigualdades, tendo como cenário as passeatas que se realizaram em todo o Brasil, em junho de 2013. A leitura parte da hipótese de que o conto assume, nos termos propostos por Tania Pellegrini (2018), uma postura realista sustentada em um posicionamento crítico que promove uma "representação em profundidade" da constituição social, fazendo uso de recursos estéticos pautados não na narração de fatos ou na descrição de espaços, mas na captura do modo como cada corpo se relaciona com o espaço e com outros corpos. Sob esse aspecto, a análise aqui realizada coloca em evidência a deformação do corpo como instrumento central na composição da narrativa, projetando-se na representação da cidade e das estruturas sociais que a compõem como corpo fragmentado e desigual.
\end{abstract}

PALAVRAS-CHAVE: Representação; Realismo; Ficção contemporânea; Allan da Rosa.

What body is that? The city and the real in the short story " $A$ unha encravada e o esmalte" (2016), by Allan da Rosa

\section{ABSTRACT}

This article discusses the forms of realism in contemporary Brazilian fiction and proposes an analysis of the short story "A unha encravada e o esmalte", by Allan da Rosa, observing how the fragmentation of the human body acts in the representation of the city and its inequalities taking into consideration the marches that took place throughout Brazil in June 2013. The analysis starts from the hypothesis that the short story assumes, in the terms proposed by Tania Pellegrini (2018), a realistic posture sustained in a critical position that promotes an "in-depth representation" from the social constitution, making uses of aesthetic resources based not in the narration of facts or in the description of spaces, but in capturing the way in which each human body relates to space and other bodies. In this regard, the analysis carried out here highlights the deformation of the human body as a central instrument in the composition of the narrative, projecting itself on the representation of the city and on the social structures that comprise it as a fragmented and unequal body.

KEYWORDS: Representation; Realism; Contemporary fiction; Allan da Rosa. 


\section{A literatura também traz consciência e tudo que traz}

consciência traz dores e dúvidas, né? A gente pensa que a

consciência vai trazer colchão e ela traz é arame farpado.

Allan da Rosa'

\section{Introdução}

No livro Ficção brasileira contemporânea, volume em que Karl Erik Schollhammer (2011) propõe uma síntese das tendências heterogêneas que se somam na composição do quadro da ficção brasileira produzida entre os anos 1990 e a primeira década do século XXI, um dos capítulos recebe o título "O realismo de novo". As ideias de um retorno no tempo - ou de um determinado tempo - subjaz à inscrição, na medida em que ela evoca significados históricos e traços de um paradigma estético com desdobramentos políticos específicos. Nesse sentido, a proposição de que a literatura do tempo presente pode, em uma de suas vertentes, recuperar "de novo" (SCHOLLHAMMER, 2011, p. 53) a forma realista de representação vem acompanhada de uma reflexão que procura localizar os elementos que permitem a vinculação da narrativa contemporânea a um modo de representar esteticamente a realidade que se articula a um posicionamento específico em relação à realidade social sobre a qual o texto lança luz.

É na diferença que o retorno ganha sentido ao se levar em conta que o realismo a que se refere o autor não corresponde a uma recuperação ao pé da letra do realismo histórico cuja origem, no século XVIII, liga-se à gênese do romance e ao esforço de construção de uma forma mimética representativa, capaz de representar de maneira objetiva e totalizante as tensões constitutivas das diferentes camadas sociais. Menos do que propor a construção de um excurso histórico que procure cercar as variações do termo "realismo" e suas diferentes aplicações em contextos distintos, interessa notar que, no conjunto da crítica literária que se ocupa de um suposto "novo realismo"2 na literatura brasileira dos últimos trinta anos, a discussão das formas de representação passa, quase sempre, por uma necessidade de singularização que é, ao mesmo tempo, a busca pela definição de recursos comuns às realizações do tempo presente.

Para Tania Pellegrini (2009), a "persistência de um mundo hostil" faz com que o desejo de representar de modo crítico as distintas formas de dominação e desigualdade sociais mova o ressurgimento de formas artísticas que buscam menos registrar objetivamente o real do que construir um código estético capaz de captar as relações entre indivíduo e sociedade. Assim, o realismo, descolado de uma visão datada que congela o termo nos séculos XVIII e XIX, se mantém como um posicionamento ético que sustenta uma realização estética. Em outros termos:

\footnotetext{
${ }^{1}$ Em entrevista concedida a Alexandre Graça Faria, Carolina de Oliveira Barreto, Fernanda Pires Alvarenga Fernandes e Waldilene Silva Miranda (2011).

2 Note-se que a expressão não apenas é recorrente em textos recentes sobre o tema, mas também dá título ao volume de ensaios sobre a representação da realidade na ficção contemporânea organizado por Izabel Margato e Renato Cordeiro Gomes (2012).
} 
Ainda se pode usar o conceito de realismo em literatura como o sentido de uma tomada de posição diante de novas realidades (postura), expressas justamente na característica especial de observação crítica muito próxima e detalhada do real ou do que é tomado como real (método), que em literatura não só a técnica descritiva representou e muitas vezes ainda representa, ao lado de outras, podendo, deste modo ser encontrada em várias épocas, como refração da primeira, até os dias de hoje (PELLEGRINI, 2018, p. 39).

A proposta de compreensão do realismo como articulação entre uma postura e um método é produtiva na medida em que permite à tarefa crítica justamente a possibilidade de apreensão de uma componente ética que sustente o processo de representação, atrelada a uma concepção estética que não precise - ou não deva -, necessariamente, aliar-se aos procedimentos técnicos que caracterizaram o romance realista em sua origem. Trata-se, por outro lado, de ter como ponto de partida uma "postura" por meio da qual a literatura se vê capaz de se colocar de forma crítica diante da realidade, promovendo uma "refração" (PELLEGRINI, 2018, p. 60) ou decompondo as camadas que a constituem, de modo a levar a cabo uma análise das desigualdades que ainda a caracterizam.

Neste ponto, convém inserir uma nova distinção, agora relacionada ao fato de que a produção contemporânea não se filia a um projeto político específico, o que faz com que não se possa ligar diretamente à prosa dos últimos anos a outras ocorrências da tendência realista na diacronia literária brasileira:

[...] não basta demarcar uma diferença fundamental dessa nova escrita realista em relação ao realismo histórico do século XIX, mas também, e principalmente, em relação às reformulações políticas do realismo realizadas tanto no romance regional da década de 1930 quanto na literatura urbana da década de 1970, que se colocava claramente contra o regime político da ditadura militar (SCHOLLHAMMER, 2011, p. 54).

Se a ausência de filiação a um projeto político unificador marca essa produção, também é verdade que a heterogeneidade é um traço que determina que não se possa falar em um projeto estético contemporâneo. Nesse âmbito, mesmo diante de uma clara tendência à linguagem performática ligada à incorporação de recursos midiáticos ao texto narrativo, há realizações que permitem que se afirme tratar de um "pacto reformulado com o realismo histórico", como faz Schollhammer (2012, n.p.) diante dos romances Habitante irreal (2011), de Paulo Scott, e Desde que o samba é samba (2012), de Paulo Lins. Assim, cabe à exegese crítica um trabalho que realize a análise de cada caso, cotejando-o com a diversidade das formas de seu tempo, o que permite não apenas a delimitação de poéticas individuais, mas também a definição do que as coloca sob traços comuns ou as distancia em pontos de dissonância.

Tendo como ponto de partida a discussão das formas de realização do realismo na ficção brasileira contemporânea, a reflexão aqui apresentada propõe uma análise do conto "A unha encravada e o esmalte", de Allan da Rosa, de modo a observar como a fragmentação do corpo atua na representação da cidade e de suas desigualdades, tendo como cenário as passeatas que se realizaram em todo o Brasil em junho de 2013. Publicada inicialmente em 21 de junho de 2013, na seção "À beira da palavra" da Revista Fórum, e posteriormente incluída no volume de contos 
Reza de mãe, lançado em 2016, a narrativa é composta por trinta parágrafos reunidos em dez grupos, ao modo de trípticos. Sem um enredo organizado que disponha fatos em uma ordem cronológica, a determinação do tema e a unidade do texto advêm do subtítulo do conto "(junho, 2013)", parêntesis que funcionam como uma determinação temporal e, ao mesmo tempo, uma ancoragem dos elementos narrativos a um fato externo específico: de antemão, apresenta-se a informação de que o material que se seguirá refere-se ao mês de junho de 2013. O leitor atento pensará na ebulição das capitais brasileiras em passeatas conjuntas; aquele um pouco menos perspicaz, logo receberá outros elementos para fazê-lo.

Cada um dos dez trípticos que compõem o conto de Allan da Rosa corresponde a uma parte do corpo flagrada durante uma ação que a singulariza: enquanto um tornozelo caminha, outro descansa sobre a calçada, e um terceiro recebe massagem. Assim, unidas pelo subtítulo, cada parte se localiza na cidade de São Paulo, passível de identificação por uma única menção ao bairro de Pinheiros, sob uma grande ação comum que reverbera nos blocos narrativos - logo no início do texto se saberá que esses corpos estão inscritos e escritos na cidade e nos desdobramentos dos atos cívicos motivados pelo reajuste da passagem de ônibus na capital: "Com uma mão, mesmo com punho cerrado passo bilhete na catraca e pago só três merréis. Foram sete passeatas pra isso, mas nas últimas veio gente com remela, nem escovou os dentes, acordou agorinha com o controle entornado no peito" (ROSA, 2016, p. 85).

Vista sob a perspectiva de cada uma dessas partes fragmentadas de corpos anônimos, a cidade é representada a partir de um movimento no interior do qual oscilam a vontade coletiva e o interesse individual, marcados pelo investimento subjetivo que move cada corpo em sua ação. Se o olhar utópico do pobre que acredita fazer parte de um momento histórico de transformação social soma-se ao influxo conservador que desfere o chute contra um homossexual na multidão, a imagem que se cria na narrativa é a de um corpo coletivo desigual, que em sua pluralidade é rasurado pela indiferença social, pela violência de gênero e por preconceitos de toda ordem. Em síntese, o conto de Allan da Rosa constrói uma visada crítica que se orienta em duas direções: de um lado, observa-se a multiplicidade da natureza dos interesses imiscuídos nas passeatas de junho, revelando a falácia de parte dos discursos que as definiram como apartidárias ou sem determinação ideológica específica; de outro, em um espectro mais amplo, entram em cena a própria cidade e seus desníveis.

\section{Um corpo, vários corpos}

Em A invenção do cotidiano (1998), ao discutir a diferença de perspectiva posta entre aquele que se coloca sobre o World Trade Center e o pedestre, Michel de Certeau opõe a posição do observador voyeur à prática do caminhante que circula pelas ruas da cidade e conhece seus becos e seus interditos, o olhar panorâmico coloca-se como metáfora da construção de um quadro no qual o observador não está implicado, ou seja, aquele que, do alto de um edifício, vê a metrópole no horizonte não tem seu corpo envolto pela cidade. A distância que protege, anulada na trajetória do pedestre que constrói táticas de apropriação do urbano por meio da circulação de seu 
corpos sobre o asfalto, em calçadas precárias, paralelepípedos irregulares ou jardins planejados, transforma-se na vivência que impregna o corpo com a cidade e seus cheiros - o combustível queimado, a comida dos camelôs ou as árvores floridas que amenizam o caminhar pelas ruas arborizadas em um bairro de classe média alta. Como em Um lugar ao sol (2009), filme de Gabriel Mascaro sobre a vida da elite brasileira em coberturas de luxo nas capitais do país, quem olha a cidade de cima não mistura seu corpo à multidão, evita a imersão no cotidiano e em seus meandros, transformando o movimento que constitui cada uma das práticas urbanas em paisagem.

Nesse sentido, a já bastante conhecida oposição do historiador francês entre o observador e o pedestre carece de uma reflexão que leve em conta a dimensão do corpo na relação com a cidade. Não o corpo como cápsula que protege o sujeito da exterioridade, mas o corpo como dispositivo de interação, de transformação, que interfere no espaço ao mesmo tempo que recebe as marcas de sua ação: "a pele, e tudo mais que se segue - junto ao corpo e à cidade -, esconde uma condição pulsante de fronteira. Em cada pedaço do percurso há alguma iminência de convocação da vivência da alteridade, de abertura ao outro. As fronteiras são permeadas por esse risco: o outro" (HISSA e NOGUEIRA, 2013, p. 57).

A cidade de Allan da Rosa, no conto "A unha encravada e o esmalte", é construída a partir da relação do espaço com o corpo, um corpo estranho, inicialmente disforme, que precisa ser compreendido em sua multiplicidade, justamente para que não se perca de vista o domínio da alteridade que rasura o investimento subjetivo que se move sob a pele de quem caminha. $\mathrm{O}$ início da narrativa se dá com um estranhamento diante desse corpo que vivencia a cidade, já que à mão que registra o pagamento do bilhete de ônibus, no primeiro parágrafo, somam-se outras duas:

\footnotetext{
Com a outra mão aperto garganta de vampiro: devolve meu sangue, seu cariado! Ele pode ter meu vermelho há séculos no bigode ou pode ser uma sereia desdentada, o que importa é alguém para esgoelar.

Com a terceira mão levo pra orelha um saco de feijão. Me entucho de fubá pelo umbigo. Vou à forra. Mas por onde mastigar? Sei levar pra boca é meu celular ultra, neon conectado ao futuro cinza. Comer as fotos. Garfo uma bombeta gringa e me empanturro. Bebo a gasolina do meu carango novo de 90 prestações (ROSA, 2016, p. 85).
}

A narrativa em primeira pessoa cria a expectativa de que essa voz pertence a um sujeito em específico, justamente aquele que transpõe as catracas para fazer uso do transporte público em seu deslocamento pela cidade. Mais do que uma conjugação verbal sem consequências para além do domínio formal, a escolha do verbo que estrutura a narrativa tem implicações semânticas fundamentais para o processo de narração, já que a opção “[...] não é feita entre duas formas gramaticais, mas entre duas atitudes narrativas (de que as formas gramaticais são apenas uma consequência mecânica): fazer contar a história por uma de suas personagens ou por um narrador estranho a essa história" (GENETTE, s/d, p. 243). Assim, a inserção de uma terceira mão no relato de um narrador que conta sua trajetória pela cidade deforma o corpo de quem fala e inicialmente projeta sobre a leitura o signo do grotesco. No segundo tríptico, outro mem- 
bro - agora o pé - se multiplica em três, na composição corporal do narrador, e faz com que a pergunta “que corpo é esse?" comece a ganhar uma nova dimensão:

Um pé meu é a mira, o boy caindo de queixo na rasteira. Vai rasgar bandeira de Palmares o caramba! O outro pé espera doação de meia e chuteira.

E o terceiro chutou aquele pichador que escreveu 'ladrões' no caixa. Passou um pano com detergente na porta do banco onde baderneiro escarrou. Dever é deixar tudo em órdi depois da nossa festa cívica. E é verdade que os magnata ajuda, bancam a festa da democracia, o voto ano sim, ano não (ROSA, 2016, p. 85).

Mesmo que não se constitua um enredo linear na sobreposição de cada parágrafo do trecho, fica evidente que as motivações que movem a ação dos membros do corpo são diferentes, como se cada pé caminhasse em uma direção distinta. Nesse ponto, entra em cena a formação de um corpo coletivo, constituído na narrativa a partir de sucessivas metonímias: cada parte corresponde a uma pessoa, a uma subjetividade, a uma experiência distinta com a cidade. Assim, enquanto um personagem encena a ação de quem revida uma agressão simbólica com violência física - o corpo supostamente negro, que luta pela defesa de sua identidade e do direito de existir ante aquele que destrói a bandeira de sua história -, outro representa a periferia que aguarda uma ação social e, por fim, o corpo subalterno, que chuta o manifestante que expressou sua insatisfação contra o sistema financeiro, defende os projetos de quem o domina, sem perceber que o financiamento bancário de campanhas e partidos subjuga seus interesses à hegemonia do capital.

Se uma única voz fala por esse corpo coletivo, a construção da narrativa deixa evidente que os pontos de vista correspondem à partição dos membros. A linguagem estruturada a partir da variante coloquial da língua, com a conjugação do verbo no singular diante de um sujeito no plural, faz emergir a perspectiva do segurança do banco que toma os manifestantes como "baderneiros". O mesmo se pode dizer em relação à exclamação que marca o tom de raiva daquele que desfere um chute, no primeiro parágrafo do bloco.

O subtítulo do conto projeta sua função na inserção das ações no contexto das manifestações de junho de 2013, somando-se ao primeiro parágrafo da narrativa, em que a menção às "sete passeatas" para pagar "três merréis" (ROSA, 2016, p. 85) circunscreve temporalmente as ações: trata-se de uma passeata posterior ao posicionamento do então prefeito da cidade São Paulo, Fernando Haddad, e do governador do Estado, Geraldo Alckmin, que revogaram o aumento da passagem. O dado é importante, na medida em que se articula à pluralidade de pontos de vista inscritos nessa voz coletiva:

Consultados sobre os motivos que os levaram até o protesto, $56 \%$ mencionaram a posição contrária ao aumento da passagem. Uma parcela de $40 \%$ disse estar no evento para protestar contra a corrupção, $31 \%$, contra a repressão/violência policial e $27 \%$ mencionaram estar no protesto por um transporte de melhor qualidade, entre outros motivos citados (LARGO, 2013, on-line).

As partes do corpo que compõem o domínio coletivo fazem com que a fragmentação da narrativa corresponda à fragmentação do público das manifestações. Destaca-se, assim, a dissocia- 
ção entre a voz que unifica esse corpo e a perspectiva, responsável pela pluralização dos olhares e a representação das subjetividades envolvidas nos protestos. A pulverização de pautas correspondeu, nos desdobramentos das manifestações de junho de 2013, a um fortalecimento dos influxos conservadores que se organizavam na sociedade brasileira sob o desenrolar de ações sociais progressistas do governo, desde a primeira eleição do ex-presidente Lula. A partir dos protestos e, sobretudo, sob o discurso da luta contra a corrupção, essa onda ganharia espaço e culminaria no golpe de 2016, que destituiu a presidenta Dilma Rousseff do cargo, e no resultado do pleito de 2018, quando Jair Bolsonaro assume o poder. Interessa, nesse sentido, observar que o conto de Allan da Rosa revela justamente a dissonância dos interesses e a violência de grupos que, entre aqueles que se moviam pelo sonho de uma sociedade mais equânime, aniquilavam corpos.

O trecho abaixo, embora longo, merece destaque porque põe em evidência a oposição entre uma utopia social que se mostra ingênua e a brutalidade da elite conservadora:

\footnotetext{
Nossos filhinhos inda vão ter escola boa, sem forca pra nóis. Com cabelo branco, ainda vamo contar na janta pros neto quase tudo dessa noite histórica. Agora é aproveitar que meu gigante acordou! Uma unha, encravada, agoniza quando roça no bico da bota da firma. Que eu vim de avental cheio de graxa mesmo.

Outra unha sonha o esmalte importado do shopcent. Já tenho a sandália guardadinha esperando pra estrear na quermesse.

A terceira unha deve tá contaminada, infeccionando. Que rasgamo teta de puta decotada porque nóis é macho e tem que manter o respeito nessa zona. Onde é que vai parar isso aqui? Devia estuprar essa vaca, mas demo uma lambuja (ROSA, 2016, p. 86).
}

Trata-se, como se pode notar, da metonímia que dá título ao conto. A unha encravada, dentro da bota da firma, traz para o grupo que protesta o trabalhador que acredita participar de um movimento democrático em que a luta social é homogênea e pode garantir um futuro mais digno para os filhos, que dependem dos serviços públicos para ter acesso à educação de qualidade. Ao lado dele, contrastam o shopping center, reduto do capitalismo e dos bens de consumo, e a quermesse, festa de rua normalmente organizada por paróquias religiosas nos meses de junho e julho para angariar fundos para as igrejas: o desejo de exibir o esmalte importado em um espaço popular articula o sonho de consumo a uma prática normalmente atribuída às classes menos favorecidas.

A oposição mais emblemática neste tríptico, porém, coloca-se entre o primeiro e o terceiro parágrafos. À luta social opõe-se a força física, marcada pela ação de um homem contra uma mulher, tomada como "puta" por usar uma roupa decotada. O conservadorismo e a pauta de costumes dão o tom, e o personagem, que pensa que pode ter contaminado sua unha por tocar o corpo da mulher, procura impor seu conceito de ordem e de respeito, rebaixando o outro, que passa a ser visto como aquele que merece ser violentado por supostamente desviar-se de um padrão de comportamento tomado como ideal: no interior do corpo coletivo, o corpo da diferença é rasgado. Aqui, se a violência física inscreve a cidade no corpo, o significado dessa marca se potencializa quando se leva em conta o último parágrafo do tríptico seguinte, momento em que a mesma personagem aparece amamentando com o peito violentado: "O terceiro [peito], ainda 
arranhado pelos manifestantes que me chamaram de vagabunda, serve leite inflamado pelo bico rasgado. Bonito ela mamar dormindo" (ROSA, 2016, p. 86).

O corpo violentado, inflamado, contrasta com a frase final, em que a perspectiva da mulher impõe o enternecimento diante da filha que mama enquanto dorme. Trata-se, como se vê, de uma narrativa de contrastes que se constroem pela sobreposição de elementos, aglutinados em blocos que delimitam ações e pontos de vista distintos. A fragmentação do corpo físico, para que se componha a metonímia do corpo coletivo, faz com que se tenha, no conto de Allan da Rosa, menos enredo e mais ações simultâneas, como se cada parágrafo correspondesse a um pequeno instantâneo que se dá no meio da multidão, ou quando este ou aquele personagem já se encontra em casa, depois de cumprido o "dever cívico". Sendo a soma de fragmentos que ganham unidade na composição da coletividade, a narrativa não coloca em cena a representação de uma totalidade descrita em detalhes objetivos ou cenas contínuas capazes de enredar sucessivas ações. Pelo contrário, trata-se da simultaneidade, do caótico e do múltiplo. O real, aqui, não é pacificado em uma representação que se quer mimética. Cada corpo fragmentado, deformado, é uma peça de um grande caleidoscópio, o corpo coletivo que sintetiza ao mesmo tempo que pluraliza a relação entre corpo e cidade.

\section{0 urbano, o real}

Leonardo Sakamoto (2013) chama atenção para a constituição da manifestação ocorrida no dia 20 de junho de 2013, justamente aquela que se deu depois da revogação do preço da tarifa e que, fracionada, aos pedaços, aparece na narrativa de Allan da Rosa. A observação do jornalista aponta para a multiplicidade de interesses que moveram diferentes grupos no interior da manifestação, colocando na ordem do dia a heterogeneidade que compunha a massa de pessoas que caminharam pela cidade de São Paulo, naquela quinta-feira. Ao lado do Movimento Passe Livre, que liderou a pauta de reivindicações antes da revogação do reajuste e, então, propunha transporte grátis para estudantes, movimentos partidários exibiam bandeiras que dividiam espaço com as cores verde e amarelo, empunhadas por aqueles que se misturaram ao coletivo para reivindicar o que se pode entender como a supressão da coletividade em favor da primazia do individual e do hegemônico:

\footnotetext{
Esse grupo sentiu-se à vontade para agir em público exatamente da mesma forma que já fazia nas áreas de comentários de blogs e nas redes sociais, mas sob o anonimato. Alguns até atacaram - de forma verbal e física - militantes de partidos e sindicalistas presentes no ato. Engana-se, porém, quem afirma que essa era uma massa fascista e uniforme (SAKAMOTO, 2013, p. 84).
}

Se a falta de uniformidade foi a marca dessa manifestação - assim como de outras que compuseram as diferentes passeatas de reivindicações em 2013 -, o conto de Allan da Rosa institui um olhar para o conjunto que, simultaneamente, toma-o como um todo, o corpo coletivo que se apropria da cidade por meio da junção de interesses díspares e o enxerga em suas microestruturas, o que evidencia a constituição de um tecido desigual, que costura experiên- 
cias com o urbano, distintas e conflitantes. Sob esse aspecto, a proposição de Peter Pál Pelbart (2000), que retoma o conceito de cidade subjetiva de Félix Guattari para afirmar que cidade e subjetividade devem ser tomadas como elementos constitutivos de uma exterioridade estruturante, interessa à leitura que aqui se está fazendo, na medida em que permite a apreensão de uma relação entre corpo e cidade transpassada por uma determinação subjetiva que não é apenas interior ou abstrata: "Mil platôs chega a sugerir que a cidade é a exterioridade por excelência, ou a forma da exterioridade. Daí porque pensar a cidade e a subjetividade deveria ser uma e mesma coisa, desde que ambas fossem remetidas à exterioridade que lhes é comum" (PELBART, 2000, p. 45).

Tomada sob o signo da exterioridade, a dimensão subjetiva das práticas urbanas engendra movimentos de apropriação do espaço que, se por um lado põem em cena um conceito específico de cidade - aquele em que o direito de usufruir dos espaços é reivindicado por uma ação coletiva de transformação para o usufruto coletivo -, por outro, acaba por evidenciar os limites dessa coletividade, já que os pés que caminham em direções contrárias não podem conduzir a um mesmo ponto de chegada ou, se assim se preferir, os interesses envolvidos no modo como cada grupo tem acesso a este ou àquele espaço da cidade escancaram o fato de que nem toda a cidade é para todos.

O corpo esquartejado funciona, na narrativa, como metáfora da constituição múltipla de membros da coletividade. De volta à reflexão sobre os modos de representação do real na ficção brasileira contemporânea, convém destacar que Schollhammer (2011) identifica um desafio da literatura brasileira recente, qual seja, o de trazer a lume a desigualdade e as formas de dominação que constituem a realidade social no Brasil por meio de experiências estéticas que não caiam em estratégias já largamente incorporadas pela mídia ou pelo mercado cultural. A questão que se coloca diz respeito à desautomatização do consumo da violência e da brutalidade cotidianas, firmado como forma de atender ao desejo de violência e de realidade de espectadores ávidos pela vida alheia, seja ela tornada exótica em narrativas televisivas de romantização da pobreza e superação das dificuldades pelo esforço desmedido, seja nos mais variados formatos de espetacularização do cotidiano das esferas marginais:

Trata-se, então, de um deslocamento claro em relação à tradição realista, mesmo que esta permaneça presente, em que a procura por novas formas de experiência estética se une à preocupação com o compromisso de testemunhar e denunciar os aspectos inumados da realidade brasileira contemporânea. É claro que tal tendência procura demarcar seu espaço dentro de uma "sede" geral de "realidade", que, com facilidade, se verifica igualmente nos grandes meios de comunicação (SCHOLLHAMMER, 2011, p. 57).

Em outros termos, a colocação do crítico pode ser vista sob a perspectiva de Pellegrini (2018), já aqui descrita. Se a "postura" realista persiste ao longo do tempo e se baseia essencialmente no desejo do escritor de manter-se fincado na realidade social, fazendo do texto uma forma de representação das assimetrias e das relações de poder do tempo presente ou de qualquer outro tempo, o método corresponde justamente às soluções - ou escolhas - estéticas que enformarão esse desejo. Nesse caso, o impasse do autor contemporâneo estaria justamente na necessidade 
de encontrar uma forma que, na expressão de seu conteúdo, não se prenda aos recursos mobilizados pelo realismo em sua gênese, cuja dimensão mimética foi colocada em xeque pelas vanguardas do início do século XX, e também não caia na armadilha criada por um mercado que transformou o hiper-realismo em garantia de vendagem de produtos esvaziados de qualquer possibilidade de reflexão sobre o real ou, de maneira mais ampla, sobre as possíveis relações entre sujeito e realidade.

Não se trata, portanto, de buscar na narrativa de Allan da Rosa uma das formas de representação do urbano que, na literatura brasileira, consolidou-se a partir das produções de João Antônio e Rubem Fonseca, nos anos 60 e 70 do século XX. Mesmo o uso da primeira pessoa no processo de narração revela um distanciamento entre o modo como se estruturou essa tendência, que Antonio Candido (2000), em ensaio de 1979, chamaria de "ultrarrealismo" e de "realismo feroz". Naquele momento - e aqui é importante destacar que estamos a quatro décadas do contexto de publicação das narrativas que deram azo às colocações do crítico -, Candido localizava no efeito de imediatismo da primeira pessoa, sem a mediação do narrador em terceira pessoa, a renovação formal que garantiria maior crueza na representação das relações de violência nas grandes cidades: "A brutalidade da situação é transmitida pela brutalidade do seu agente (personagem), ao qual se identifica a voz narrativa, que assim descarta qualquer interrupção ou contraste crítico entre narrador e matéria narrada" (CANDIDO, 2000, p. 212-213).

Um exemplo emblemático é o conto "O cobrador", de Rubem Fonseca, publicado também em 1979 e tomado pela crítica como paradigmático da representação da cidade por meio da violência na ficção do autor. No conto, cabe ao protagonista - que cobra da alta sociedade tudo aquilo que não teve por morar na periferia e não ter oportunidade de acesso à educação, à saúde e a condições mínimas de habitação - narrar de maneira descritiva cada uma das mortes promovidas como paga para sua condição:

Curva a cabeça, mandei.

Ele curvou. Levantei alto o facão, seguro nas duas mãos, vi as estrelas no céu, a noite imensa, o firmamento infinito e desci o facão, estrela de aço, com toda minha força, bem no meio do pescoço dele.

A cabeça não caiu e ele tentou levantar-se, se debatendo como se fosse uma galinha tonta nas mãos de uma cozinheira incompetente. Dei-lhe outro golpe e mais outro e a cabeça não rolava. Ele tinha desmaiado ou morrido com a porra da cabeça presa no pescoço (FONSECA, 1989, p. 20).

Na narrativa de Rubem Fonseca, um ponto de vista centralizador é posto a serviço da representação da relação entre sujeito e cidade: cabe ao agente da violência a voz para narrar, e nisto reside parte da inovação do autor, que insere na literatura o cotidiano de sujeitos marginalizados. Longe de trazer para a leitura de "A unha encravada e o esmalte" um olhar para a literatura marginal que procura dar ênfase ao fato de que se trata, aqui, de uma literatura produzida pela periferia - afinal, esse não é o objetivo posto para a discussão -, o que se pretende colocar em pauta é que, no caso específico desse conto, o uso da primeira pessoa pluraliza os pontos de vista. Mais do que isso, é necessário falar de uma articulação entre a escolha da voz narrativa e 
a recuperação de duas técnicas caras às vanguardas artísticas: a fragmentação do corpo e a fragmentação do texto.

\section{Considerações finais}

Se a fragmentação da forma correspondeu à tentativa de captação da realidade moderna caótica e veloz, sobretudo em sua aproximação com o movimento das grandes cidades, também correspondeu a um esforço de representação aliado à percepção de que a própria realidade não poderia ser apreendida pelo homem de maneira totalizante e unificadora. Assim, da geometrização dos Cubistas ao romance modernista brasileiro de Oswald de Andrade, a fragmentação projeta no objeto artístico a permeabilidade dos processos de representação à experiência com o real, não mais centralizada na razão cartesiana e agora sustentando o que Anatol Rosenfeld (1996) identificaria como "desrealização" nas artes plásticas e na literatura modernas.

No caso do conto que aqui se está discutindo, esse processo de fragmentação das instâncias narrativas, com a consequente suspensão do enredo, articula-se à deformação do corpo, recurso caro aos Surrealistas e às tentativas de objetificação do humano ou, ainda, de produção de estranhamento no interior de algo já conhecido, como nas proposições de Freud acerca do "infamiliar"'. Deslocado de seu contexto e de seu uso pelas vanguardas, este último recurso funciona, na narrativa de Allan da Rosa, como solução estética para a representação das distintas relações estabelecidas entre corpo e cidade no interior de uma manifestação pública de reivindicação por melhores condições de circulação. Fragmentado, o corpo é metonímia de cada uma das subjetividades exteriorizadas em uma tentativa de desempenhar um papel ativo diante da cidade, integrando-se a ela.

Sob esse aspecto, "A unha encravada e o esmalte" não apenas traz à tona a desigualdade do corpo coletivo que corresponde à própria cidade, mas também - e a reboque desse movimento - põe em xeque a apropriação da cidade pelas camadas populares, que precisam circular por ela e para quem a possibilidade de ir e vir corresponde, no limite, a uma possibilidade de existência na cidade. Sendo a força da luta popular rasurada - e rasgada - pela ação violenta de grupos conservadores e pela polícia repressora que atua a mando do Estado, não se pode negar que é a própria dinâmica dos processos históricos de transformação da cidade que está sendo representada na narrativa de Allan da Rosa, afinal, “[...] a ideia de que a cidade poderia funcionar como um corpo político coletivo, um lugar no interior do qual e a partir dele movimentos progressistas poderiam surgir, parece implausível" (HARVEY, 2012, p. 82).

Para David Harvey, que retoma as proposições de Henri Lefebvre, o direito à cidade é coletivo porque depende de uma força transformadora conjunta que garanta aos sujeitos a possibilidade de mudar a própria vida a partir do redimensionamento urbano. Sendo corpo e cidade uma relação íntima de constituição e de troca em que as fronteiras entre a prática do espaço e o modo como esse mesmo espaço interfere naquele que o experiencia, a construção de um corpo coleti-

\footnotetext{
3 Termo proposto por Ernani Chaves e Pedro Heliodoro Tavares na tradução de Das Unheimliche, de Freud (2019).
} 
vo põe em evidência, justamente, o poder que pode ser investido à organização reivindicatória de um grupo organizado. Ocorre, porém, que o esquartejamento desse corpo e a violência contra o indivíduo, incorporados pela narrativa de Allan da Rosa, escancaram as fissuras que separam os interesses de diferentes grupos sociais no interior desse conjunto, colocando em questão a impossibilidade de existência de uma totalidade coesa em torno do bem comum. Assim, a lógica de funcionamento das estruturas sociais no interior de um dado cotidiano específico - e cabe destacar que o conto foi escrito e publicado inicialmente no mesmo mês em que ocorreram as manifestações públicas, no ano de 2013 - atua como uma nova metonímia na narrativa, qual seja, a da própria organização social brasileira e suas ambiguidades no contexto que antecede o impeachment da presidenta Dilma Rousseff, um dos principais fatos históricos do início do século XXI, no Brasil.

Assim, a fragmentação narrativa e a deformação do corpo servem como instrumento de representação dessas ambiguidades. Longe de uma forma representativa, mimética e totalizante, "A unha encravada e o esmalte" faz do contraste e da pluralidade, postos em instantâneos somados à composição do todo, o método de apreensão e representação estética da realidade, diante da qual o escritor mantém uma postura de observação crítica, afastada de um olhar exótico ou espetacularizador. De dentro da passeata, cada parte do corpo fala por uma voz que o constitui e, se ao leitor resta o incômodo permanente de reconhecer a desigualdade e a violência como fatores que impossibilitam a existência de um corpo coletivo unificado - como a dor tenaz de uma unha encravada -, a ele também é dada a consciência de que a luta existe. Heterogêneo, esse corpo segue sendo a cidade. E a literatura se reinventa e atualiza - pela inovação ou pela recuperação de formas passadas - seu modo de representá-la.

\section{REFERÊNCIAS}

CANDIDO, Antonio. A nova narrativa. In: CANDIDO, Antonio (Org.). A educação pela noite e outros ensaios. 3. ed. São Paulo: Ática, 2000. p. 199-215.

CERTEAU, Michel de. A invenção do cotidiano: artes de fazer. Tradução por Ephraim Ferreira Alves. 3. ed. Petrópolis: Vozes, 1998.

FARIA, Alexandre Graça; BARRETO, Carolina de Oliveira; FERNANDES, Fernanda Pires Alvarenga; MIRANDA, Waldine Silva. A parabélum e o passarinho. ENTREVISTA / Allan da Rosa. Darandina, Juiz de Fora, 25 jul. 2011. Disponível em: <https://www.uff.br/darandina/files/2011/07/Entrevista-Allan-da-Rosa. pdf>. Acesso em: 28 abr. 2021.

FONSECA, Rubem. O cobrador. 3. ed. São Paulo: Companhia das Letras, 1989.

FREUD, Sigmund. O infamiliar. Tradução por Ernani Chaves e Pedro Heliodoro Tavares. São Paulo: Autêntica, 2019.

GENETTE, Gérard. Discurso da narrativa. Tradução por Fernando Cabral Martins. Lisboa: Vega, s./d.

HARVEY, David. O direito à cidade. Tradução por Jair Pinheiro. Lutas sociais, s.v., n. 29, p. 73-89, jul./dez. 2012. 
HISSA, Cássio Eduardo Viana; NOGUEIRA, Maria Luísa Magalhães. Cidade-corpo. Revista Universidade Federal de Minas Gerais, v. 20, n. 1, p. 54-77, jan./jun. 2013.

LARGO da Batata reuniu 65 mil, a maioria novatos na onda de protestos. Instituto DATAFOLHA, Opinião pública, São Paulo, 19 jun. 2013. Disponível em: <https://datafolha.folha.uol.com.br/opiniaopublica/2013/06/ 1297654-largo-da-batata-reuniu-75-mil-a-maioria-novatos-na-onda-de-protestos.shtml $>$. Acesso em: 28 abr. 2021.

LINS, Paulo. Desde que o samba é samba. Rio de Janeiro: Planeta, 2012.

MARGATO, Izabel; GOMES, Renato Cordeiro. (Orgs.). Novos realismos. Belo Horizonte: Editora UFMG, 2012.

PELBART, Peter Pál. Cidade, lugar do possível. In: A vertigem por um fio: políticas da subjetividade contemporânea. São Paulo: FAPESP/Iluminuras, 2000. p. 43-52.

PELLEGRINI, Tania. Realismo: a persistência de um mundo hostil. Revista da ABRALIC, v. 11, n. 14, p. 11$36,2009$.

PELLEGRINI, Tania. Realismo e realidade na literatura: um modo de ver o Brasil. São Paulo: Alameda, 2018.

ROSA, Allan da. Reza de mãe. São Paulo: Nós, 2016.

ROSENFELD, Anatol. Reflexões sobre o romance moderno. In: ROSENFELD, Anatol (Org.). Texto/Contexto I. 5. ed. São Paulo: Perspectiva, 1996. p. 75-97.

SAKAMOTO, Leonardo. Em São Paulo, o Facebook e o Twitter foram às ruas. In: VAINER, C. et alii. Cidades rebeldes: passe livre e as manifestações que tomaram as ruas do Brasil. São Paulo: Boitempo, 2013. p. 83-87.

SCHOLLHAMMER, Karl Erik. Ficção brasileira contemporânea. 2. ed. Rio de Janeiro: Civilização Brasileira, 2011.

SCHOLLHAMMER, Karl Erik. Pacto renovado com a história. Revista Ciência Hoje, 04 ago. 2012. Disponível em: <https://cienciahoje.org.br/artigo/pacto-renovado-com-a-historia/>. Acesso em: 28 abr. 2021.

SCOTT, Paulo. Habitante irreal. Rio de Janeiro: Alfaguara, 2011.

UM LUGAR ao sol. Direção de Gabriel Mascaro. Brasil: Símio, 2009. 1 DVD (71 min.), son., color. 